\title{
Aspects of testing the adhesion ability of microorganisms from oral cavity to common impression materials used in implant - prosthetic rehabilitation
}

\author{
Gabriel CIOCHINDA ${ }^{1}$, MD, PhD student, Lorelai Georgeta BILINSCHI ${ }^{2}, \mathrm{MD}$, \\ Lecturer Gabriela TANASE ${ }^{1}$, MD, Lecturer Claudia-Camelia BURCEA ${ }^{1}, \mathrm{MD}_{\text {, }}$ \\ Univ. Assist. Viorel Stefan PERIEANU ${ }^{1}, \mathrm{MD}$, Assoc. Prof. Mihai BURLIBASA ${ }^{1}, \mathrm{MD}, \mathrm{PhD}$, \\ Univ. Assist. Magdalena DINA ${ }^{1}$, MD, Univ. Assist. Madalina Violeta PERIEANU ${ }^{1}, M^{2}$, \\ Univ. Assist. Radu COSTEA ${ }^{1}$, MD, Raluca COSTEA ${ }^{3}$, MD, Prof. Dana Cristina BODNAR ${ }^{1}, \mathrm{MD}, \mathrm{PhD}$, \\ Assoc. Prof. Liliana BURLIBASA ${ }^{4}, \mathrm{MD}, \mathrm{PhD}$, Lecturer Traian BODNAR ${ }^{1}, \mathrm{MD}$, \\ Univ. Assist. Oana EFTENE ${ }^{1}$, MD, Assoc. Prof. lleana IONESCU ${ }^{1}, \mathrm{MD}, \mathrm{PhD}$ \\ 1"Carol Davila" University of Medicine and Pharmacy, Bucharest \\ ${ }^{2}$ S.C. LIODENT CLINIQUE S.R.L., Sibiu \\ ${ }^{3}$ S.C. Dentexpert Magic S.R.L., Brasov \\ ${ }^{4}$ Faculty of Biology, University of Bucharest
}

\begin{abstract}
Purpose. The adhesion ability of microorganisms present in the oral microbial plaque is a certainty for solid surfaces at this level (including coronal restorations, classical prosthetic restorations and implantsupported restorations fixed and mobile, orthodontic appliances). Therefore, in this study, we have attempted to demonstrate the ability of these microorganisms from the oral cavity to adhere on the surface of some common impression materials used in implant-prosthetic rehabilitation.

Material and method. The study was conducted on the main impression materials used in implant supported prosthetic restorations as well as in dental medicine: irreversible hydrocolloids, zinc oxide eugenol pastes, polyethers, condensation and addition silicones. The study was conducted between June and July 2017.

Results and discussions. With the help of microorganisms isolated from the 87 patients, an inoculation of standard samples of impression materials was performed. Verification of adherence was achieved at different time intervals, the results being significant.

Conclusions. For the tested materials, it was noted that the degree of adhesion was either influenced by the products incorporated in the base substance or by the secondary products resulted from chemical setting of material.
\end{abstract}

Keywords: implanto-prosthetic rehabilitation, impression materials, adherence, microorganisms

\section{INTRODUCTION}

As is well known, implant supported prosthetic restorations, classical dental prosthetics, as well as orthodontics and dentofacial orthopedics are basic specialties of dental medicine, where almost any work done involves direct contact with the existing secretions in oral cavi- 
ty (blood, saliva, gingival crevicular fluid etc.) (1-4).

Thus, in this paper, we will try a more special approach of infectious risk in dental medicine, with particular reference to implant-prosthetic rehabilitation, classical dental prosthetics, as well as orthodontics and dentofacial orthopedics, having as a starting point dental impression and impression materials (1-8).

\section{PURPOSE}

The dental plaque is the most important and aggressive microbial biofilm present in the oral cavity. This dental microbial plaque is present on virtually all solid surfaces in the oral cavity, starting from teeth and ending with various filling materials, and also implants supported or clasic prosthetic restorations fixed and/or mobile used for treatment of various type of edentations.

Specifically, in this study we attempted to perform a test of the adhesion ability of some microorganisms present in the dental microbial plaque existing in the oral cavity, on the surface of some common impression materials in implant supported prosthetic restorations, in classical dental prosthetics, as well as in orthodontics and dentofacial orthopedics (1-12).

\section{MATERIALS AND METHODS}

Impression materials tested in this study were irreversible hydrocolloids, zinc oxide eugenol paste, polyethers, addition silicones (putty and light body) and condensation silicones (putty and light body). All these impression materials are used primarily in implant-prosthetic rehabilitation dental prosthetics, but some of these (see irreversible hydrocolloids) are also used in orthodontics and dentofacial orthopedics.

These materials were prepared as instructed and cut into small pieces with a specially adapted device ( $5 \mathrm{~mm}$ diameter). All tests regarding the adhesion of microorganisms on the surface of the aforementioned impression materials were performed for each individual product.

In the pre-test phase, the following types of microorganisms, oral streptococci, belonging to the species originally colonizing the dental surfaces, were isolated from the microbial dental plaque from 87 patients in July-July 2017: T63.2 Streptococcus sp., T47 Streptococcus mitis, T123 Streptococcus acidomonas, T41.6 Streptococcus sp., T33.3 Enterococcus faecium, T48 Streptococcus acidominimas, T41.1 Actinomyces naeslundii, T42.1 Gemella morbillorum, T110 Actinomyces naeslundii, T62.1 Streptococcus mitis, T67 Staphylococcus epidermidis, T73 Staphylococcus sp., T50 Pasteurella haemolytica [the letter $T$ with digits is indicative of these samples, thus $T=$ strain and the accompanying number is the number of the isolated sample (microbial strains of the same genus)].

This test was carried out as follows: over the impression material surface was placed a standardized bacterial inoculum ( $0.5 \mathrm{McF}$ (arland) for different periods of time, then the material fragment was washed lightly (to remove unadherent bacteria) and was placed in a tube with 500 $\mu \mathrm{l}$ of physiological saline, and centrifuged to detach the adhering bacteria. Quantification of bacteria was done by determining the number of colony-forming units per milliliter. Contact times were: 2 minutes, 5 minutes, 10 minutes, 30 minutes, 60 minutes and 120 minutes. As mentioned previously, the isolated microorganisms were: Streptococcus acidominimus, Staphylococcus epidemidis, Gemella morbillorum, Actinomyces naeslundii and Enterococcus faecium.

Thus, we have opted for these microbial strains (considered to be primary colonizers) in conducting adherence studies on the surface of common impression materials in implant supported and classic prosthetic restorations, and also in orthodontics and dentofacial orthopedics because these microorganisms will be the first and most important to colonize the selected impression materials during the time they are into the oral cavity until the chemical setting phenomenon is completed (1-12).

\section{RESULTS}

In terms of testing the adhesion of microorganisms to the usual dental impression materials mentioned above used in implant supported reabilitation, as well as in orthodontics and dentofacial orthopedics, this was done for the microorganisms used: Streptococcus acidominimus, Staphylococcus epidemidis, Gemella morbillorum, Actinomyces and Enterococcus faecium. The results were illustrated very suggestively in the following charts.

After setting reaction, the composition of the putty condensation silicone inhibits the adhesion of microbial strains for a contact time of 10 and 30 minutes, possibly due to the second- 


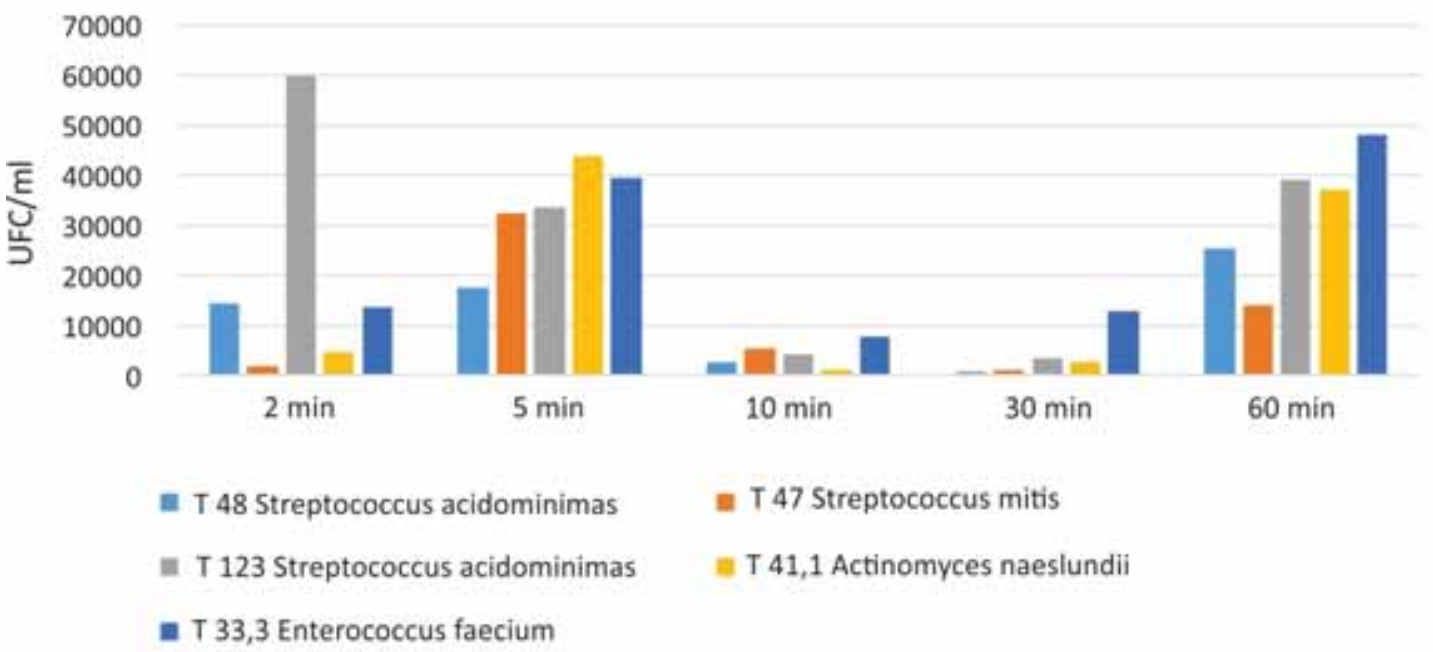

FIGURE 1. The number of colony-forming units developed on putty condensation silicone graphical representation

ary products resulting from the condensation reaction (polymerization) from alcohols group present in its structure. However, this inhibitory reaction product is not strong enough, the bacteria adapting to its presence, colonizing the surface in case of a longer exposure time (Fig. 1)

The analysis of the number of colony forming units developed on the two types of condensation silicone indicates that the putty type (see Fig. 1) is less favorable to microbial adherence than light body type at time intervals of 10 and 30 minutes respectively (see Fig. 2) and this may be due to a higher concentration of secondary products as a result of the condensation (polymerization) reaction from the alcohol family (with one or more -OH groups) in the case of putty condensation silicon, compared to light body condensation silicone.

Regarding putty and light body addition silicones, it is noted that colony-forming unit's number has a lower development for the light body type (Fig. 4) compared to the putty type (Fig. 3), which may be due to some secondary products as a result of the addition reaction (polymerization) also from class of alcohols, a product that is likely to be in increased concentration in the structure of light body type, compared to the putty type. As in the case of the putty condensation silicone, the lowest number of recovered bacteria was after a $\mathbf{3 0}$ minute contact (for putty condensation silicone, we actually talk of 10 and respectively 30 minutes) (see Fig. 1 and Fig. 4).

Regarding the irreversible hydrocolloid, we can say that due to the fairly porous structure of this impression material, the number of colony-forming units adhering to this material is quite irregular: we have a very low number for certain microbial strains at 10 and 30 minutes respectively for T47 Streptococcus mitis (proba-

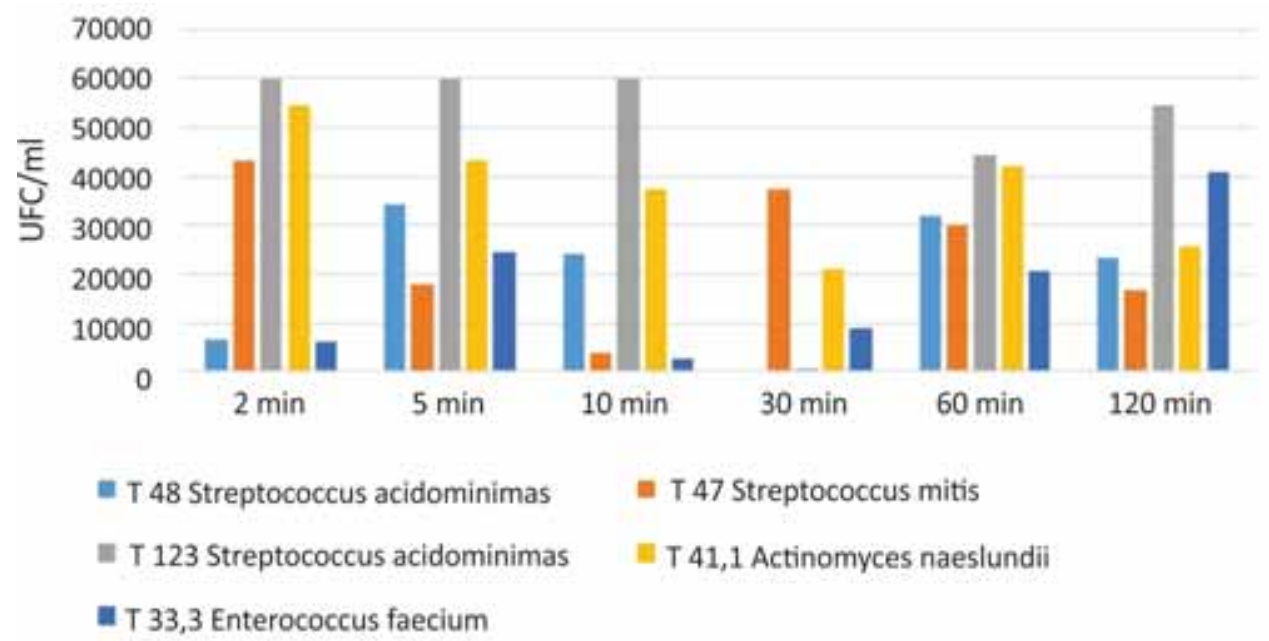

FIGURE 2. The number of colony-forming units developed on light body condensation silicone graphical representation 


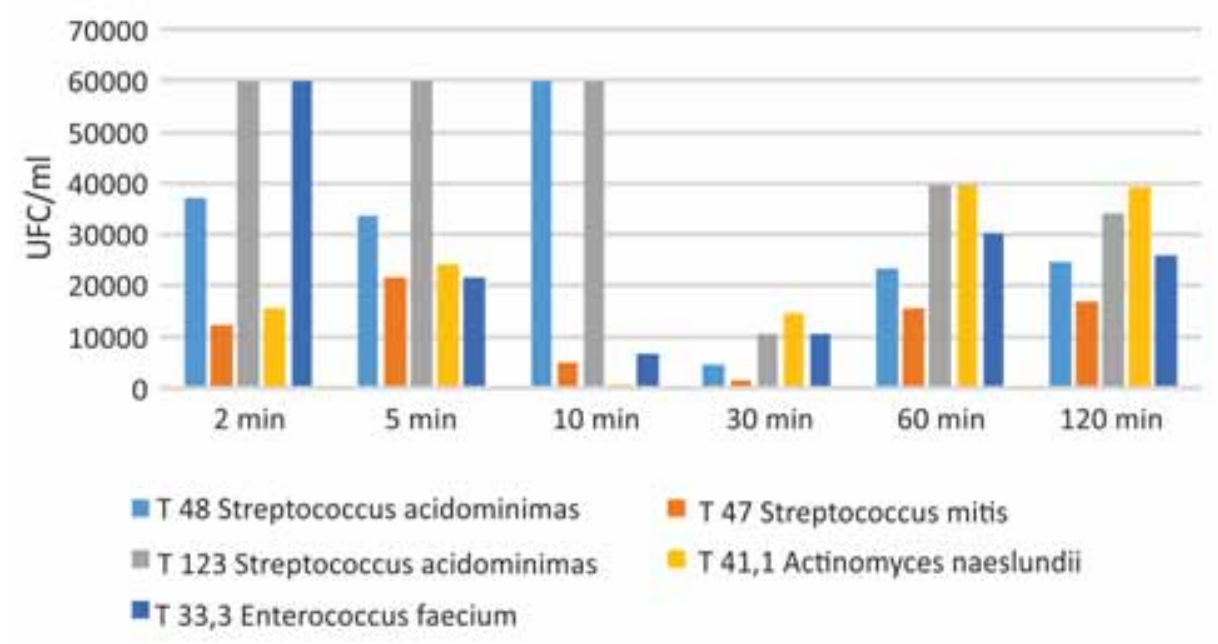

FIGURE 3. Graphical representation of colony-forming units' number developed on putty addition silicone

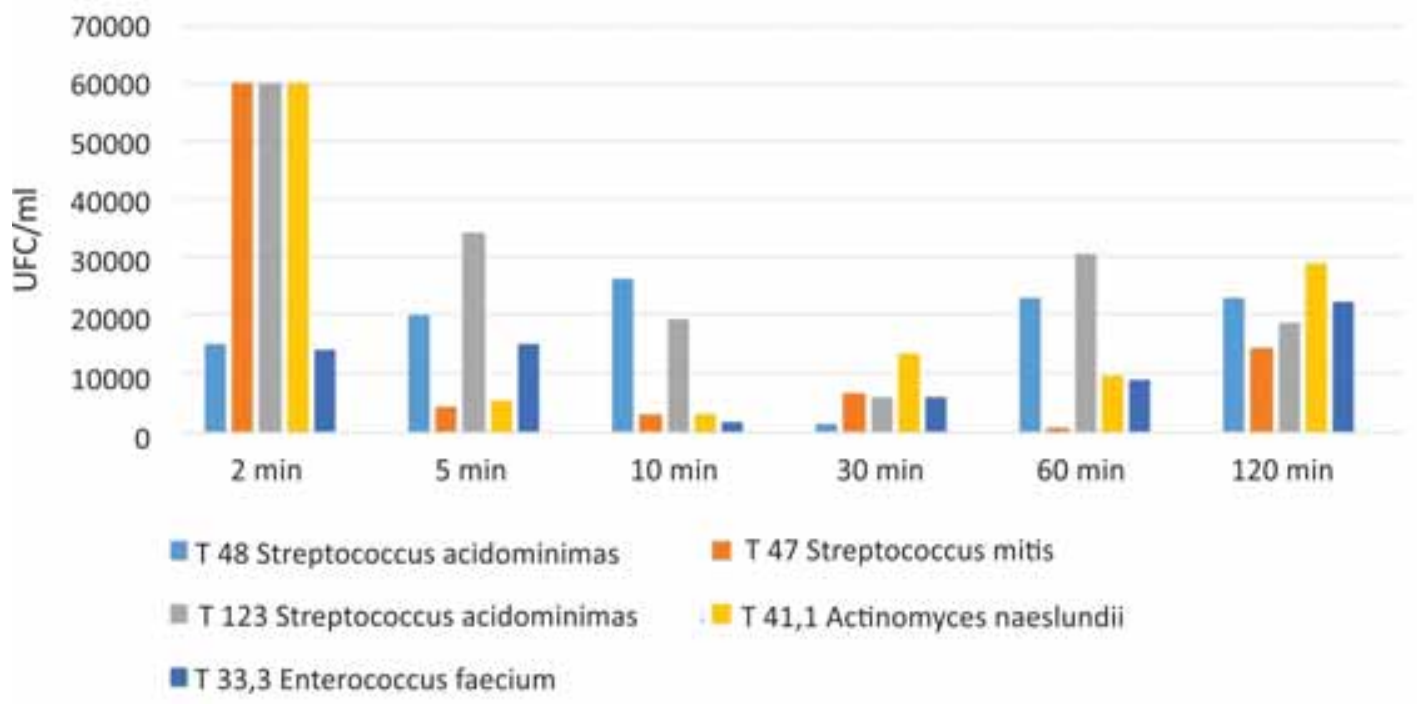

FIGURE 4. Graphical representation of colony-forming units' number developed on light body addition silicone.

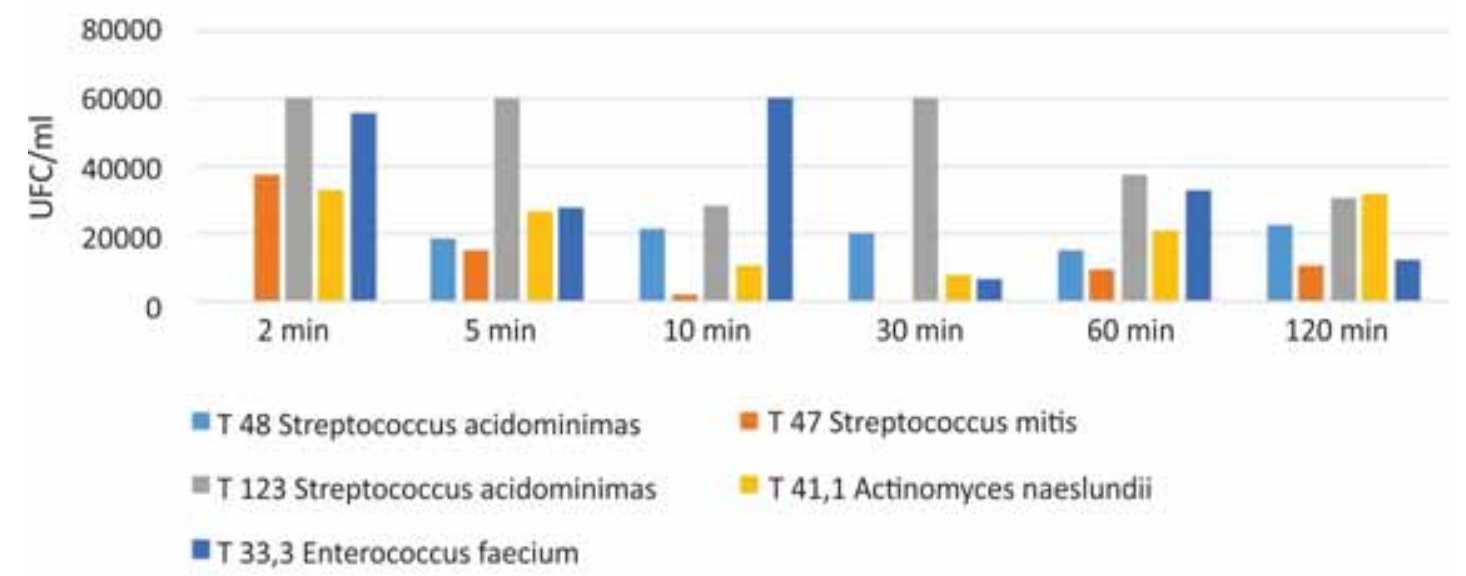

FIGURE 5. Graphical representation of colony-forming units' number developed on irreversible hydrocolloid (alginate). 


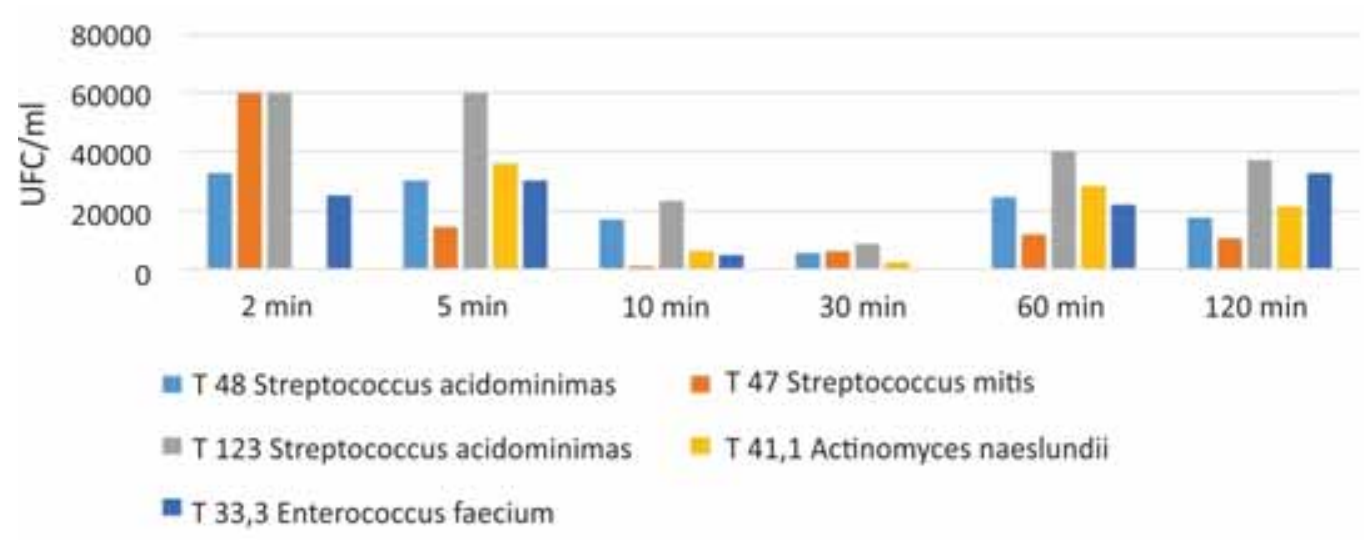

FIGURE 6. Graphic representation of colony-forming units' number developed on zinc oxide eugenol impression paste

bly due to antiseptic substances incorporated in the structure of the impression material to increase the antibacterial potential of the irreversible hydrocolloid without the manufacturer mentioning it in the package leaflet) and mean at 10 and 30 minutes respectively for T.41 Actinomyces naeslundii. Otherwise, we find high to very high values for the other microbial strains and for all the time periods studied.

As we mentioned in the first part of this larger study, the main component of Eugenia caryophyllata extract - eugenol - is known for its antimicrobial and antibiotic properties, being used in dentistry in the root canal filling process (13).

The presence of eugenol in the composition of the zinc oxide eugenol paste actually provides a decrease of colony forming units' number, especially in the range of 10 and 30 minutes, respectively, compared to the other tested materials (Fig. 6) (13).

In the case of polyether it can be noticed a high increase of colony-forming units number at the first contact times ( 2 and 5 minutes respec- tively), but it can be noticed a drastic reduction of colony-forming units number at $\mathbf{3 0}$ minutes (Fig. 7) (14-24).

\section{CONCLUSIONS}

After studying the results obtained, several conclusions could be drawn, among which we will mention the ones that we have appreciated as the most important:

Impression materials from the silicone family, whether they are condensation or addition, do not exhibit excessive microbial adherence due to alcohol based secondary reaction products that can inhibit this microbial adhesion mechanism.

Irreversible hydrocolloids, due to their porous structure, favor the adhesion of microorganisms from the mouth in very large concentrations. Producers of impression materials have attempted to reduce this microbial adherence by incorporating various disinfecting chemicals into the structure of irreversible hydrocolloids.

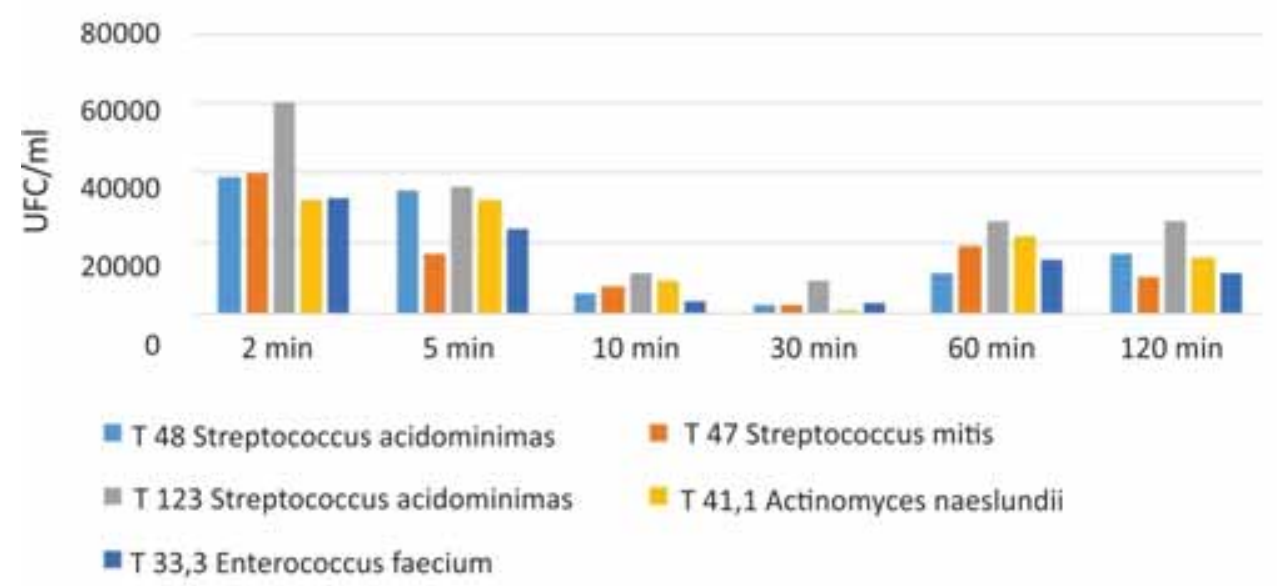

FIGURE 7. Graphical representation of colony forming units' number developed on the polyether 
Due to the presence of eugenol in the structure, the zinc oxide eugenol pastes inhibit adherence of microbial colonies to the surface of these types of impression material.

\section{Acknowledgement}

In this article, all the authors have equal contributions.

\section{REFERNCES}

1. Timoșca S.-F. Microbiologie stomatologică. Litografie I.M.F. Iași 1987, pag. 245-247.

2. Lazăr V. Aderența microbiană. Editura Academiei Române, București, 2003.

3. Zijnge V., Van Leeuwen M.B.M., Degener J.E. et al. Oral biofilm architecture on natural teeth. PLoS ONE. 5(2): e9321, 2010.

4. Wood S.R., Kirkham J., Marsh P.D. et al. Architecture of intact natural human plaque biofilms Studied by Confocal Laser Scanning Microscopy. J Dent Res. 79: 21-27, 2000.

5. Kolebrander P.E., Andersen R.N., Blehert D.S. et al. Communication among oral bacteria. Microbiol Mol Biol Rev. 1 September 2002, Vol. 66, No. 3, pp. 486-505.

6. Avila M., Ojcius D.M., Yilmaz O. The oral microbiota: Living with a permanent guest. DNA Cell Biol. August 2008, 28(8): 405-411.

7. Palmer T., Berks B.C. Moving folded proteins across the bacterial membrane. Microbiology. March 2003, 149(Pt 3): 547-556.

8. Dige I., Raarup M.K., Nyengaard J.R. et al. Actinomyces naeslundii in initial dental biofilm formation. Microbiology. July 2009, 155(Pt 7): 2116-2126.

9. Li D., Gurkovska V., Sheridan M. et al. Studies on the regulation of the twocomponent histidine kinase gene CHK1 in Candida albicans using the heterologous lacZ reporter gene. Microbiology. October 2004, 150(Pt 10): 3305-3313.

10. Diaz P.I., Chalmers N.I., Rickard A.H. et al. Molecular charcterization of subject- specific oral microflora during intial colonization of enamel. Applied and environmental microbiology. April 2004, Vol. 72, Issue 4, pp. 2837-2848.

11. Wright J.J., Kishori M., Hallam S.J. Microbial ecology of expanding oxygen minimum zones. Nature Reviews Microbiology. June 2012, 10, pp. 381-394.

12. Lee K.G., Shibamoto T. Antioxidant property of aroma extract isolated from clove buds (Syzygium aromaticum (L) Merr. Et. Perry). Food Chemistry. 2001, 74, 443-448.

13. Bersan S.M.F., Galvão L.C.C., Goes O.F.F. et al. Action of essential oils from Brazilian native and exotic medicinal species on oral biofilms. BMC Complement Altern Med. 2014, 14: 451.

14. Cristache C.M., Burlibașa M., Tănase G. et al. Titanium as dental implant material. Metalurgia International 14, 2009, 14-16.

15. Ștețiu A.A., Oleksik M., Oleksik V. et al. Mechanical behavior of composite materials for dental obturations. Romanian Biotechnological Letters 18(4), 2013, 8528-8538.

16. Bodnar D.C., Pantea M., Bodnar T. et al. Patologia mucoasei orale la pacienții vârstnici - studiu clinico-statistic. Acta Medica Transilvanica 2(2), 2012, 56-60.

17. Bodnar D.C., Dimova C., Bodnar T. et al. Dental management of patient with psychiatric disorders. Modern Medicine 17(10), 2010, 538-543.

18. Mocuta D., Popovici L.R., Dumitriu A.S. et al. Life quality-condition of social welfare. Metalurgia International 14, 2009, 62-64.
19. Burlibașa M., Burlibașa L., Gavrilă L.B. et al. MicroRNA a macro Revolution in Medical Biotechnologies. Romanian Biotechnological Letters 13(6), 2008, 3977-3983.

20. Burlibasa M., Cernusca-Mitariu M., Cernusca-Mitariu S., Malita M. Theoretical and practical aspects related to biomaterials decontamination in dental medicine (with reference to dental prosthetics). Metalurgia International. Vol. XVIII, No. 4, 2013, pp. 261-267.

21. Tanase G., Burlibasa M., Muntianu L.A.S. et al. Testing the antibacterial potential of biomaterials in medical practice. Metalurgia International. Vol. XV, Spec Iss No. 2, 2010, pp. 160-162.

22. Burlibasa M., Muntianu L.A.S., Tanase G. et al. Study on microbial contamination of biomaterials in medical practice. Metalurgia International. Vol. XV, Spec. Issue No. 2, 2010, pp. 163-166.

23. Bilinschi L.G., Perieanu V.S., Perieanu M.V. et al. Isolation, identification and characterization of adhesion and development capacity of biofilms in microbial strains insulated in patients functionally rehabilited with fixed prosthetic restaurations. Acta Medica Transilvanica. Vol. 22, No. 4, 2017, pp. 97-100.

24. Bilinschi L.G., Perieanu V.S., Perieanu M.V. et al. Testing of microorganisms sensitivity to impression materials commonly used in dental prosthodontics. Acta Medica Transilvanica. Vol. 22, No. 4, 2017, pp. 110-112. 